\title{
Safety and technical efficacy of over-the-wire balloons for the treatment of subarachnoid hemorrhage-induced cerebral vasospasm
}

\author{
Anna Terry, M.Sc., Gregory Zipfel, M.D., Eric Milner, DeWitte T. Cross III, M.D., \\ Christopher J. Moran, M.D., Michael N. Diringer, M.D., RalPh G. DaCeY JR., M.D., \\ AND COLIN P. DERDEYN, M.D.
}

\author{
Departments of Neurological Surgery, Neurology and Interventional Neuroradiology Service, \\ Mallinckrodt Institute of Radiology, Washington University School of Medicine, St. Louis, Missouri
}

\begin{abstract}
Object. Over the past decade, low-pressure, flow-directed balloons have been replaced by over-the-wire balloons in the treatment of vasospasm induced by subarachnoid hemorrhage (SAH). The authors assess the procedural safety and technical efficacy of these newer devices.

Methods. Seventy-five patients who underwent 85 balloon angioplasty procedures for the treatment of SAHinduced vasospasm were identified from a prospective quality-assurance database. Medical records and angiographic reports were reviewed for evidence of procedural complications and technical efficacy.

No vessel rupture or perforation occurred, but thromboembolic complications were noted in four $(4.7 \%)$ of the 85 procedures. Balloon angioplasty was frequently attempted and successfully accomplished in the distal internal carotid (100\%), proximal middle cerebral (94\%), vertebral (73\%), and basilar (88\%) arteries. Severe narrowing was present in 89 proximal anterior cerebral arteries. Angioplasty was attempted in 41 of these vessels and was successful in only $14(34 \%)$. In 19 of the 27 unsuccessful attempts, the balloon could not be advanced over the wire due to severe vasospasm or unfavorable vessel angle. Follow-up angiography in a subset of patients demonstrated that severe recurrent vasospasm occurred in $15(13 \%)$ of 116 vessels studied after angioplasty.

Conclusions. Over-the-wire balloons involve a low risk for vessel rupture. The anterior cerebral artery remains difficult to access and successfully treat with current devices. Further improvements in balloon design, such as smaller inflated diameters and better tracking, are necessary. Finally, thromboembolic complications remain an important concern, and severe vasospasm may recur after balloon angioplasty.
\end{abstract}

KEY WORDS • vasospasm • ischemic stroke • subarachnoid hemorrhage • angioplasty

$\mathrm{S}$ EVERE narrowing or vasospasm of the large arteries at the skull base is a common delayed phenomenon after $\mathrm{SAH}{ }^{25}$ This narrowing may result in reduced cerebral blood flow and tissue ischemia owing to interrelated physiological processes, including a reduction in distal perfusion pressure and, often, distal autoregulatory dysfunction. ${ }^{26}$

Zubkhov first reported the use of intravascular balloons to dilate these focal stenoses. ${ }^{27}$ Further technical developments in balloon design led to widespread clinical use. ${ }^{4,7,8,20,21}$ Eskridge and colleagues ${ }^{7}$ reported the first large clinical series of cases in which balloon angioplasty was used in the treatment of SAH-induced vasospasm. The balloon used in this series was a low-pressure (0.5-atmosphere) silicone balloon mounted on the tip of a microcatheter (Interventional Therapeutics Corp., later Boston Scientific/Target Therapeutics, Natick, MA). It was not a

Abbreviations used in this paper: $\mathrm{ACA}=$ anterior cerebral artery; $\mathrm{BA}=$ basilar artery; $\mathrm{CT}=$ computed tomography; $\mathrm{EVD}=$ external ventricular drain; ICA = internal carotid artery; $\mathrm{MCA}=$ middle cerebral artery; $\mathrm{SAH}=$ subarachnoid hemorrhage; $\mathrm{VA}=$ vertebral artery. guidewire-directed system, although a wire could be introduced into the balloon to deflect the direction of the balloon tip. ${ }^{8}$

During the last decade, several over-the-wire, low-pressure balloons have been introduced. ${ }^{9}$ These new devices offer the potential to access more difficult anatomical sites than did the original nondetachable balloons. In this paper, we report on the results of our investigation of the procedural safety and technical efficacy of the newer devices. The primary procedural risks of balloon angioplasty are vessel rupture or guidewire-caused perforation and thromboembolic phenomena leading to distal infarcts. Technical efficacy is defined as the ability to access and treat the target stenosis.

\section{Clinical Material and Methods}

This study was a retrospective review of clinical data pertaining to cases identified from a database of all diagnostic and therapeutic endovascular procedures performed at the Mallinckrodt Institute between June 1995 and June 2006. This database is maintained by the Interventional Neuroradiology Service for quality-assurance purposes. 
Approval was obtained from the human studies committee for waiver of informed consent.

\section{Patient Selection}

The database was reviewed to identify patients who underwent attempted or successful balloon angioplasty for the treatment of SAH-induced vasospasm. Patients treated with tip-mounted balloon catheters (Interventional Therapeutics Corp. or Endeavor [Boston Scientific Corporation, Natick, MA]) were excluded. Patients treated with vasodilators only were excluded, unless balloon angioplasty was also attempted during the same procedure. Patients presenting with unsecured aneurysms and severe vasospasm treated during the endovascular aneurysm obliteration procedure were also excluded.

\section{Endovascular Vasospasm Treatment}

At our institution, all patients with suspected symptomatic cerebral vasospasm undergo catheter angiography. Transcranial Doppler ultrasound is not used for screening. Depending on the clinical situation and severity of symptoms, hypervolemic hypertensive therapy may be instituted prior to the angiographic diagnosis of vasospasm.

A No. 5 or 6 French arterial sheath is used for all procedures. Diagnostic angiography is performed using No. 5 French diagnostic catheters. Both common carotid arteries and a VA are injected selectively, and the images are compared to those from the initial angiographic study performed at the time of SAH diagnosis. Vasospasm is subjectively graded as mild, moderate, or severe. ${ }^{17}$ After vasospasm is angiographically diagnosed, a choice is made between medical and endovascular treatment. This decision is reached through discussion among the attending interventional neuroradiologist, neurosurgeon, and neurointensivist. In general, if moderate or severe vasospasm is present in a vessel referable to the patient's symptoms and the condition is amenable to angioplasty (that is, involved vessels are accessible by endovascular means), balloon angioplasty is pursued. Attempts are made to treat all accessible vessels that are affected by moderate to severe vasospasm, even if symptoms are clearly referable to a single vessel territory. Vasodilators are used for the treatment of vessels that cannot be treated with balloons..$^{23}$

General anesthesia is often used, depending on the amount of patient movement, intubation status, and the perceived technical difficulty of balloon angioplasty. Heparin is administered systemically to increase the activated clotting time to twice the patient's baseline measurement, unless there is a significant contraindication. The recent or remote placement of an EVD is not considered a contraindication to heparinization. Hypervolemic hypertensive therapy is maintained if it was instituted prior to the procedure. ${ }^{1,18}$

A No. 5 French guide catheter or diagnostic catheter is advanced into the target ICA or VA. After placement of the catheter, vasodilators are sometimes infused prior to angioplasty if blood flow is particularly slow. Papaverine hydrochloride was used in most of the cases in this series. ${ }^{16}$ Verapamil has been used more recently after concerns regarding the toxicity of papaverine were raised. ${ }^{1,2,14,15,24} \mathrm{~A}$ variety of balloon catheters were employed (see Table 3 ). The choice of balloon is at the discretion of the operator.
As a result of current device availability and performance, in the majority of the cases and all recent procedures, we have used the Hyperglide balloon (EV3 Inc., Plymouth, MN). This balloon has a low profile and can be advanced through a No. 5 French diagnostic catheter. The balloon is tested and prepared with a $50 \%$ contrast solution prior to placement, and it is advanced over a wire that occludes the distal tip and allows balloon inflation. Selection of vessels is performed using fluoroscopic landmarks, such as bone or aneurysm clips or coils, or with roadmapping techniques. After proper placement through the area of stenosis, the balloon is inflated and immediately deflated as soon as the target diameter is reached. The balloon has a maximum inflated diameter of $4 \mathrm{~mm}$. Angioplasty of vessels smaller than $4 \mathrm{~mm}$ is accomplished with careful subtotal inflation. Angioplasty is not attempted for vessels distal to the proximal segments of the MCA $\left(\mathrm{M}_{1}\right)$, ACA $\left(\mathrm{A}_{1}\right)$, or posterior cerebral artery $\left(\mathrm{P}_{1}\right)$.

Control angiography is performed after angioplasty to assess treatment results, distal spasm, and thromboembolic complications. Vasodilator infusions through the guide catheter or a microcatheter are frequently performed to treat residual distal spasm. At the conclusion of the procedure, the catheter is removed and systemic heparin administration is either discontinued or reversed. The sheath is removed at that time or several hours later in the intensive care unit, and hemostasis is achieved through manual compression.

\section{Chart Review}

The quality assurance database included each patient's name, sex, and date of birth, as well as the date of the procedure, names of the devices employed, and information on the occurrence of any procedural complications. The medical records and angiographic reports were obtained for patients who met the inclusion criteria for the present study. Information gathered for this study included the date of SAH (if known), cause of SAH, Hunt and Hess grade, Fisher grade, aneurysm location (in cases of aneurysmal $\mathrm{SAH}$ ), mode of aneurysm therapy, date of endovascular therapy for vasospasm, details of the endovascular procedure, and whether an EVD was placed or other neurosurgical procedure was performed prior to vasospasm treatment.

Procedural details included the vessels involved by moderate to severe vasospasm, the number of these vessels targeted for balloon angioplasty, and the number in which balloon angioplasty successfully restored vessel diameter. We considered the distal ICA, the VA and BA, the $\mathrm{M}_{1}$ segment, and the $A_{1}$ segment to be amenable to angioplasty, unless otherwise stated. Reasons given in the reports for not treating accessible vessels in severe spasm were recorded. The use of general anesthesia and heparin was recorded, as was the adjunctive use of vasodilators. Any procedural complications were recorded.

\section{Durability of Balloon Angioplasty}

We reviewed the reports from all follow-up angiograms or repeat balloon angioplasty procedures performed within 2 weeks after the initial angioplasty procedure. ${ }^{19}$ The presence of moderate or severe vasospasm at sites that had been previously treated was recorded. 


\section{Safety and Technical Efficacy}

The primary safety measurements in this study were the occurrence of vessel rupture from balloon inflation or wire perforation and thromboembolic complications. Other complications were also recorded, including any evidence of arterial injury (dissection) or groin hematoma requiring transfusion or surgical repair. Reports from postprocedural CT scans were reviewed for any evidence of intracerebral hemorrhage along the EVD track. The primary technical end point was successful treatment of accessible vessels.

\section{Data Analysis}

All data were recorded on an Excel (Microsoft Corp., Redmond, WA) spreadsheet for analysis. Complication rates were reported as a percentage of procedures performed. Technical success rates were reported as a percentage of target vessels involved by vasospasm.

\section{Results}

\section{Demographic Characteristics}

Demographic characteristics of the patients are summarized in Table 1. Seventy-five patients (22 men and 53 women) underwent 85 balloon angioplasty procedures using over-the-wire balloons between June 1995 and June 2006. Their mean age was 47 years (range 16-73 years). The mean Hunt and Hess grade was III. The cause of SAH was aneurysmal in 69 patients (see Table 2 for locations). In the remaining six patients, the cause of SAH was traumatic carotid cavernous fistula (two patients), arteriovenous malformation (one patient), or unknown (three patients). Forty-six of the patients with ruptured aneurysms underwent craniotomy for clip placement and 23 were treated endovascularly with detachable coils. One of the aneurysms was treated with both coil and clip placement.

TABLE 1

Characteristics of patient population

\begin{tabular}{|c|c|}
\hline Variable & Value \\
\hline \multicolumn{2}{|l|}{ sex (no. of patients) } \\
\hline male & $22(29.3 \%)$ \\
\hline female & $53(70.7 \%)$ \\
\hline \multicolumn{2}{|l|}{ age (years) } \\
\hline mean & 47.2 \\
\hline median & 47 \\
\hline range & $16-73$ \\
\hline \multicolumn{2}{|l|}{ lesion severity } \\
\hline mean Fisher grade & $3.48 *$ \\
\hline mean Hunt \& Hess grade & $\mathrm{III} \dagger$ \\
\hline \multicolumn{2}{|l|}{ aneurysm treatment } \\
\hline clip application & 46 \\
\hline coil embolization & 26 \\
\hline balloon occlusion & 1 \\
\hline \multicolumn{2}{|l|}{$\begin{array}{l}\text { preangioplasty surgical procedures } \\
\text { (no. of patients) }\end{array}$} \\
\hline EVD & $42(56.0 \%)$ \\
\hline decompressive craniectomy & $6(8.0 \%)$ \\
\hline \multicolumn{2}{|l|}{ follow-up angiography (no. of patients) } \\
\hline available & 38 \\
\hline unavailable & 37 \\
\hline 2nd angioplasty attempt required & 10 \\
\hline
\end{tabular}

TABLE 2

Locations of lesions in 75 patients with $\mathrm{SAH}^{*}$

\begin{tabular}{lc}
\hline \hline \multicolumn{1}{c}{ Lesion Location } & No. of patients \\
\hline anterior circulation aneurysm & $56(74.7 \%)$ \\
ACoA & 19 \\
PCoA & 16 \\
ICA & 9 \\
MCA & 6 \\
ACA & 2 \\
pericallosal artery & 2 \\
superior hypophyseal artery & 1 \\
AChA & 1 \\
posterior circulation aneurysm & $13(17.3 \%)$ \\
VA/BA & 8 \\
PICA & 5 \\
nonaneurysmal & $6(8.0 \%)$ \\
traumatic carotid-cavernous fistula & 2 \\
frontotemporal AVM & 1 \\
no aneurysm found & 3 \\
\hline
\end{tabular}

$* \mathrm{ACh} \mathrm{A}=$ anterior choroidal artery; $\mathrm{ACoA}=$ anterior communicating artery; $\mathrm{AVM}=$ arteriovenous malformation; $\mathrm{PCoA}=$ posterior communicating artery; PICA = posterior-inferior cerebellar artery.

Both traumatic fistulas were treated with endovascular coil placement, and one was also treated with a detachable balloon. Forty-two patients underwent EVD placement before endovascular intervention for vasospasm.

\section{Procedural Details}

Characteristics of the angioplasty procedures are summarized in Table 3. Moderate or severe vasospasm was identified on diagnostic angiography at a mean of 8 days (range 3-24 days) after SAH in these 75 patients. Thirty-

TABLE 3

Characteristics of first balloon angioplasty procedure

\begin{tabular}{|c|c|}
\hline Variable & Value \\
\hline \multicolumn{2}{|l|}{ no. of days post-SAH } \\
\hline mean & $8.6^{*}$ \\
\hline median (range) & $8(3-24)$ \\
\hline prior intubation & $27 \dagger$ \\
\hline \multicolumn{2}{|l|}{ medications } \\
\hline systemic heparin & $56 \S$ \\
\hline papaverine & 23 \\
\hline verapamil & 21 \\
\hline \multicolumn{2}{|l|}{ balloon used } \\
\hline Hyperglidell & 46 \\
\hline Cirrus】 & 8 \\
\hline Commodore** & 4 \\
\hline Equinoxll & 4 \\
\hline Sentry $\dagger \dagger$ & 4 \\
\hline Stealth $\dagger \dagger$ & 4 \\
\hline SolsticeII & 3 \\
\hline Hyperformll & 2 \\
\hline Maverick $\dagger \dagger$ & 1 \\
\hline
\end{tabular}

* Unknown in six cases.

$\dagger$ Unknown in seven cases.

$\ddagger$ Unknown in five cases.

$\S$ Unknown in 16 cases.

II Micro Therapeutics, Inc.

II Medtronic Micro Interventional Systems.

** Cordis Corporation.

$\dagger \dagger$ Boston Scientific. 
A. Terry, et al.

TABLE 4

Number and location of vessels treated with balloon angioplasty

\begin{tabular}{|c|c|c|c|c|c|}
\hline \multirow[b]{2}{*}{ Variable } & \multicolumn{5}{|c|}{ No. of Vessels Treated } \\
\hline & ICA & $\mathrm{M}_{1}$ & VA & BA & $\mathrm{A}_{1}$ \\
\hline \multicolumn{6}{|l|}{ 1st procedure } \\
\hline vasospastic & 89 & 107 & 15 & 26 & 89 \\
\hline treated & 91 & 101 & 11 & 23 & $\begin{array}{l}14 \text { successful } \\
27 \text { unsuccessful } \\
48 \text { not attempted }\end{array}$ \\
\hline $\begin{array}{l}\text { persistent vasospasm } \\
\text { at end of procedure }\end{array}$ & 8 & 16 & 0 & 2 & 28 \\
\hline $\begin{array}{l}\text { 2nd procedure } \\
\text { treated in } 1 \text { st procedure } \\
\quad(116 \text { vessels }) \\
\text { recurrent vasospasm at site } \\
\text { of angioplasty } \\
\quad(15 \text { vessels }[12.9 \%])\end{array}$ & $6(14.6 \%)$ & $5(10.0 \%)$ & 5 & 7 & $4(30.8 \%)$ \\
\hline
\end{tabular}

two endovascular procedures were performed under general anesthesia. In 27 cases, an endotracheal tube was already in place at the time of the procedure; in five others an endotracheal tube was inserted to provide general anesthesia for the endovascular procedure. Adjunctive vasodilators were administered in 44 procedures (papaverine in 23 , verapamil in 21 ).

\section{Technical Efficacy}

Table 4 shows the results of endovascular treatment by vessel territory. Balloon angioplasty was frequently attempted and successfully accomplished in the distal ICA (81 [100\%] of 89 vasospastic vessels plus two additional vessels), the $M_{1}$ segment (101 [94\%] of 107 vessels), the VA (11 [73\%] of 15), and the BA (23 [88\%] of 26 vessels). The $\mathrm{A}_{1}$ segment was severely narrowed in 89 vessels. Angioplasty was attempted in 41 of these 89 vessels and was successful in only $14(34 \%)$. The balloon could not be advanced over the wire in 19 of the 27 unsuccessful attempts. Reasons given for treatment failure or for no attempt at treatment having been made are given in Table 5 .

\section{Procedural Safety}

No instance of vessel rupture or perforation was identi-

TABLE 5

Failed or nonattempted A1 procedures

\begin{tabular}{lc}
\hline \multicolumn{1}{c}{ Reason for Failure or Nonattempt } & No. of Cases \\
\hline unable to advance balloon due to vasospasm & 19 \\
$\quad$ or unfavorable angle & 12 \\
adequate distal flow or good contralateral $\mathrm{A}_{1}$ & 9 \\
territory treated by vasodilator & 5 \\
too close to aneurysm clip & 3 \\
small size or congenital hypoplasty & 2 \\
adjacent aneurysm & 2 \\
displacement of guide catheter & 2 \\
flow restored by treatment of ICA or $\mathrm{M}_{1}$ & 2 \\
infarct in ACA distribution & \\
not symptomatic/spontaneous resolution & 2 \\
$\quad$ of vasospasm & 1 \\
flow restored by urokinase & 18 \\
not involved & 8 \\
no reason given & \\
\hline
\end{tabular}

fied in this study, but thromboembolic events occurred in four patients (Table 6). Filling defects were identified in the distal territory of the ICA on postprocedural angiography in three patients. These defects led to large MCA infarctions in two patients despite attempted thrombolysis. Both patients had been treated with systemic heparin. One patient who was not treated with systemic heparin had a single small distal branch occlusion with no clinical consequence. The fourth patient probably suffered an embolic occlusion of the distal ICA on placement of the guide catheter prior to receiving systemic heparin. Severe spasm was evident on the diagnostic angiogram. After a guide catheter was placed in the ICA, no blood flow was found beyond the ophthalmic artery. Angioplasty and thrombolytic therapy did not restore patency, and the patient suffered a large hemispheric infarction. One patient suffered a retroperitoneal hemorrhage. No intracerebral hemorrhages were identified along the path of the EVD catheter in the 42 patients who required placement of an EVD before their angioplasty procedure.

\section{Treatment Durability}

Table 4 summarizes data pertaining to the recurrence of vasospasm identified on follow-up angiography, which was performed in 38 of the 75 patients. Ten (26\%) of these 38 patients ultimately required a second balloon angioplasty procedure for the treatment of vasospasm. The risk of recurrence of moderate-to-severe vasospasm in a previously treated territory was $12.9 \%$ (15 of 116 vessels) in these patients who underwent repeat angiography. This risk

TABLE 6

Complications of balloon angioplasty

\begin{tabular}{ll}
\hline \hline \multicolumn{1}{c}{ Complication } & No. of Cases \\
\hline vessel rupture or perforation & 0 \\
postprocedure EVD track hemorrhage & 0 \\
thromboembolism & $4(4.7 \%)$ \\
retroperitoneal hematoma & $1(1.2 \%)$ \\
hypotension during procedure & 1 \\
early sheath dislodgment & 1 \\
excessive bleeding at femoral puncture site & 1 \\
\hline
\end{tabular}


was lowest in the VA and BA territories, where no evidence of recurrent vasospasm was found. Intermediate risk was found in the $\mathrm{M}_{1}$ and distal ICA segments, and high risk was found in the $\mathrm{A}_{1}$ segment, with a recurrence rate after treatment of $30.8 \%$. Recurrent vasospasm in territories initially treated with vasodilator therapy alone (that is, without balloon angioplasty) was not specifically analyzed but did occur frequently, as expected. ${ }^{10}$

\section{Discussion}

\section{Demographic Characteristics}

We reviewed our experience in 75 cases of symptomatic cerebral vasospasm treated with balloon angioplasty using new over-the-wire, low-pressure balloons. We included, in addition to patients with known aneurysmal SAH, six patients with nonaneurysmal SAH, based on the rationale that this is a study of angioplasty to treat symptomatic vasospasm, irrespective of the origin of the hemorrhage.

In general, our results reflect the preponderance of data for vessels in the anterior cerebral circulation. Not only was severe vasospasm less frequent in the posterior circulation (VA and BA), it was also successfully treated more often and persisted less often. This may be due to aneurysm location; most aneurysms occurred in the anterior circulation in our study (56 [81.2\%] of 69 cases). The grading of vasospasm as moderate or severe is subjective; we chose to include only cases with these grades because we wanted to identify patients who had vasospasm that was severe enough for treatment to be considered (vasospasm classified as mild is not usually treated).

\section{Technical Efficacy}

Our research demonstrates that balloon angioplasty has a high rate of technical efficacy in most arterial territories treated, with a success rate of greater than $90 \%$ in the distal ICA and the $\mathrm{M}_{1}$ segment. However, balloon angioplasty of the proximal ACA remains a technical challenge, with a treatment success rate of only $34 \%$. Moreover, despite significant rates of vasospasm in this territory, angioplasty was often not attempted due to technical difficulties, most prominently an unfavorable angle that prevented advancement of the balloon catheter. In some of these cases, vasospasm resolved after the administration of vasodilator medication, which provides less durable results than angioplasty. Treatment failure and technical inability to treat this territory remain important problems that may be resolved in the future by improved balloon design. The Hyperglide balloon catheter has a diameter of $4 \mathrm{~mm}$, which exceeds the average diameter of the $A_{1}$ segment (2-3 mm), increasing the risk of perforation during treatment. Smaller balloon diameters should improve safety and ability to access the $A_{1}$ segment as well as more distal segments in other territories, potentially including $\mathrm{A}_{2}$ and $\mathrm{M}_{2}$. In addition, better tracking will improve the ability to negotiate the sharp angle at the origin of the ACA. ${ }^{9}$

Although in our study the rate of technical success was high for most territories, our findings may represent an overestimate of technical success due to selection bias: easily treatable territories are more likely to be treated. ${ }^{11}$ Thus the relatively low success rate for $A_{1}$ may still be artificially inflated by the fact that patients with tortuosity or congenitally hypoplastic $\mathrm{A}_{1}$ segments were not treated due to safety concerns. In addition, some patients with tortuous $\mathrm{M}_{1}$ segments or significant carotid atherosclerosis were treated with vasodilator medication rather than angioplasty, causing a transient improvement in the vasospasm in that territory without necessarily producing durable results. Because follow-up angiography was performed in only 38 cases (50.7\%), it is difficult to assess the long-term efficacy of treatment. The temporary effects of vasodilator treatment are well recognized. ${ }^{5,6,13,14}$

\section{Procedural Safety}

Our rate of serious complications was quite low, with no instances of vessel rupture or perforation, four thromboembolic events directly attributable to the angioplasty procedure $(4.7 \%)$, one retroperitoneal hematoma (1.2\%), and no EVD track hemorrhage. Minor complications (transient hypotension, sheath dislodgment, prolonged bleeding at the puncture site) occurred in only two patients.

The complication rate may be artificially low for two reasons. First, the computerized record may be incomplete (especially before 2001), failing to reveal minor complications or delayed recognition of thromboembolic events attributable to the procedure. Second, it is often difficult to determine whether unfavorable outcomes such as new infarctions are due to thromboembolic complications of angioplasty or problems inherent to the disease process, such as ongoing vasospasm. ${ }^{3,22}$ As with technical efficacy, prospective studies are needed to assess complication rates more accurately and ensure that specific complications are recognized and recorded in a timely manner.

We observed no EVD track hemorrhages on the postprocedure CT scans. Although a CT scan of the head was not obtained in all patients within the first few days after the procedure, the absence of EVD track hemorrhages in those patients in whom CT scans were obtained is not a surprising finding, considering that most EVDs were placed shortly after hospital admission, several days before the patient's first angioplasty procedure. A recent review of aneurysm coil placement procedures performed soon after EVD placement for SAH found no difference in the risk of EVD track hemorrhage between 117 patients who were treated with coil placement and systemic heparin and 251 patients with SAH who did not receive systemic heparin or undergo coil placement. ${ }^{12}$

It is encouraging that there were no instances of vessel perforation or rupture in the cases we reviewed. Intraprocedural perforation is an easily recognizable event and would certainly be recorded in the official report, so it can be assumed that the record provides a realistic depiction of the experience at our institution. Angioplasty was not attempted beyond the large arteries of the circle of Willis, a factor that probably contributed to safety. Thus neither immediate hemorrhagic complications due to perforation or rupture nor delayed hemorrhagic complications associated with heparin administration, such as intracerebral bleeding along the EVD track, emerged in our study.

On further review of the five thromboembolic complications, we found that three patients had been treated with systemic heparin, one had not been, and one was treated with heparin only late in the procedure, after a clot was 
A. Terry, et al.

found during the diagnostic stage. Because the main argument for the use of heparin during angioplasty revolves around prevention of thromboembolism and two of the five patients with thromboembolic complications apparently were not given adequate heparin treatment, it appears that the routine use of heparin as systemic anticoagulation therapy during angioplasty is more than justified.

\section{Treatment Durability}

We found that in some cases, vasospasm did recur after balloon angioplasty (15 [12.9\%] of 116 treated vessels that were reexamined). This phenomenon was most notable in the $\mathrm{A}_{1}$ territory. As mentioned, this finding may reflect inadequate angioplasty due to technical or safety reasons (for example, concern about vessel perforation or tortuosity) or it may reflect recurrence after successful angioplasty. Our recurrence rate may be artificially high due to the fact that only half of the patients had follow-up angiographic examinations. These patients probably had symptoms indicative of recurrent or persistent vasospasm, and $10(26.3 \%)$ of these 38 patients eventually required a second balloon angioplasty procedure. Patients who did well clinically would not be as likely to undergo followup angiographic examination and therefore would not have been included in our results. Therefore, our estimate probably represents an upper limit for the risk of recurrent vasospasm.

More information about the relationship between procedural safety/technical efficacy and clinical outcomes would be welcome. We chose not to take this approach in our study because of the difficulty in determining the patient's initial clinical grade and long-term outcome from the medical record and also because of the lack of a straightforward relationship between the endovascular interventions and the patient's clinical condition. Variables (such as the severity of the initial hemorrhage, medical comorbidities, efficacy of concurrent hemodynamic therapy, and the natural progression of the disease process) may influence outcome independent of endovascular interventions. ${ }^{3,22}$ However, we did record data on the patients' estimated neurological condition on discharge, which may be used in future studies.

\section{Conclusions}

In sum, our research demonstrates a high rate of technical efficacy for balloon angioplasty except in the proximal anterior cerebral artery, where the lower success rate may be ascribed to both failure to treat and unsuccessful treatment. In the future, improved balloon technology should greatly enhance our ability to treat this vessel territory. Complication rates were low, in particular with respect to vessel rupture and intracerebral hemorrhage along the EVD track, although prospective studies are needed for more accurate assessment. The primary risk of the procedure relates to thromboembolic complications, and patients should be routinely treated with systemic heparin administration. Finally, vasospasm did occasionally recur at sites previously treated using angioplasty.

\section{Disclaimer}

None of the authors has a financial interest in any of the devices used in this study.

\section{References}

1. Andaluz N, Tomsick TA, Tew JM Jr, van Loveren HR, Yeh HS, Zuccarello M: Indications for endovascular therapy for refractory vasospasm after aneyrismal subarachnoid hemorrhage: experience at the University of Cincinnati. Surg Neurol 58:131-138, 2002

2. Carhuapoma JR, Qureshi AI, Tamargo RJ, Mathis JM, Hanley DF: Intra-arterial papaverine-induced seizures: case report and review of the literature. Surg Neurol 56:159-163, 2001

3. Corsten L, Raja A, Guppy K, Roitberg B, Misra M, Alp MS, et al: Contemporary management of subarachnoid hemorrhage and vasospasm: the UIC experience. Surg Neurol 56:140-150, 2001

4. Coyne TJ, Montanera WJ, Macdonald RL, Wallace MC: Percutaneous transluminal angioplasty for cerebral vasospasm after subarachnoid hemorrhage. Can J Surg 37:391-396, 1994

5. Dorsch NW: Therapeutic approaches to vasospasm in subarachnoid hemorrhage. Curr Opin Crit Care 8:128-133, 2002

6. Elliott JP, Newell DW, Lam DJ, Eskridge JM, Douville CM, Le Roux PD, et al: Comparison of balloon angioplasty and papaverine infusion for the treatment of vasospasm following aneurysmal subarachnoid hemorrhage. J Neurosurg 88: 277-284, 1998

7. Eskridge JM, McAuliffe W, Song JK, Deliganis AV, Newell DW, Lewis DH, et al: Balloon angioplasty for the treatment of vasospasm: results of first 50 cases. Neurosurgery 42: 510-517, 1998

8. Eskridge JM, Song JK: A practical approach to the treatment of vasospasm. AJNR Am J Neuroradiol 18:1653-1660, 1997

9. Eskridge JM, Song JK, Elliott JP, Newell DW, Grady MS, Winn HR: Balloon angioplasty of the A1 segment of the anterior cerebral artery narrowed by vasospasm: technical note. J Neurosurg 91:153-156, 1999

10. Firlik AD, Kaufmann AM, Jungreis CA, Yonas H: Effect of transluminal angioplasty on cerebral blood flow in the management of symptomatic vasospasm following aneurysmal subarachnoid hemorrhage. J Neurosurg 86:830-839, 1997

11. Fujii Y, Takahashi A, Yoshimoto T: Effect of balloon angioplasty on high grade symptomatic vasospasm after subarachnoid hemorrhage. Neurosurg Rev 18:7-13, 1995

12. Hoh BL, Nogueira RG, Ledezma CJ, Pryor JC, Ogilvy CS: Safety of heparinization for cerebral aneurysm coiling soon after external ventriculostomy drain placement. Neurosurgery 57:845-849, 2005

13. Katoh H, Shima K, Shimizu A, Takiguchi H, Miyazawa T, Umezawa H, et al: Clinical evaluation of the effect of percutaneous transluminal angioplasty and intra-arterial papaverine infusion for the treatment of vasospasm following aneurysmal subarachnoid hemorrhage. Neurol Res 21:195-203, 1999

14. Liu JK, Couldwell WT: Intra-arterial papaverine infusions for the treatment of cerebral vasospasm induced by aneurysmal subarachnoid hemorrhage. Neurocrit Care 2:124-132, 2005

15. McAuliffe W, Townsend M, Eskridge JM, Newell DW, Grady MS, Winn HR: Intracranial pressure changes induced during papaverine infusion for treatment of vasospasm. J Neurosurg 83:430-434, 1995

16. Milburn JM, Moran CJ, Cross DT III, Diringer MN, Pilgram TK, Dacey RG Jr: Effect of intraarterial papaverine on cerebral circulation time. AJNR Am J Neuroradiol 18:1081-1085, 1997

17. Milburn JM, Moran CJ, Cross DT III, Diringer MN, Pilgram TK, Dacey RG Jr: Increase in diameters of vasospastic intracranial arteries by intraarterial papaverine administration. J Neurosurg 88:38-42, 1998 


\section{Over-the-wire balloons for SAH-induced cerebral vasospasm}

18. Miller JA, Dacey RG Jr, Diringer MN: Safety of hypertensive hypervolemic therapy with phenylephrine in the treatment of delayed ischemic deficits after subarachnoid hemorrhage. Stroke 26:2260-2266, 1995

19. Murai Y, Kominami S, Kobayashi S, Mizunari T, Teramoto A: The long-term effects of transluminal balloon angioplasty for vasospasms after subarachnoid hemorrhage: analyses of cerebral blood flow and reactivity. Surg Neurol 64:122-127, 2005

20. Newell DW, Eskridge JM, Mayberg MR, Grady MS, Winn HR: Angioplasty for the treatment of symptomatic vasospasm following subarachnoid hemorrhage. J Neurosurg 71:654-660, 1989

21. Polin RS, Coenen VA, Hansen CA, Shin P, Baskaya MK, Nanda A, et al: Efficacy of transluminal angioplasty for the management of symptomatic cerebral vasospasm following aneurysmal subarachnoid hemorrhage. J Neurosurg 92: 284-290, 2000

22. Rabinstein AA, Friedman JA, Nichols DA, Pichelmann MA, McClelland RL, Manno EM, et al: Predictors of outcome after endovascular treatment of cerebral vasospasm. AJNR Am J Neuroradiol 25:1778-1782, 2004

23. Schuknecht B: Endovascular treatment of cerebral vasospasm following aneurysmal subarachnoid hemorrhage. Acta Neurochir Suppl 94:47-51, 2005
24. Smith WS, Dowd CF, Johnston SC, Ko NU, DeArmond SJ, Dillon WP, et al: Neurotoxicity of intra-arterial papaverine preserved with chlorobutanol used for the treatment of cerebral vasospasm after aneurysmal subarachnoid hemorrhage. Stroke 35:2518-2522, 2004

25. Weir B: Subarachnoid Hemorrhage: Causes and Cures. New York: Oxford University Press, 1998

26. Yundt KD, Grubb RL Jr, Diringer MN, Powers WJ: Autoregulatory vasodilation of parenchymal vessels is impaired during cerebral vasospasm. J Cereb Blood Flow Metab 18: 419-424, 1998

27. Zubkov YN, Nikiforov BM, Shustin VA: Balloon catheter technique for dilatation of constricted cerebral arteries after aneurysmal subarachnoid hemorrhage. Acta Neurochir (Wein) 70: 65-79, 1984

Received July 21, 2006.

Accepted in final form August 7, 2006.

Address reprint requests to: Colin P. Derdeyn, M.D., Washington University School of Medicine, 510 South Kingshighway Boulevard, St. Louis, Missouri 63110. email: derdeync@wustl.edu. 